\title{
Processo, representação e projeto: tópicos para uma metodologia de ensino de design fundamentada na ação e prática cotidianas
}

\author{
Process, representation and design: topics for a teaching methodology based on the \\ design and practical daily action
}

\author{
Alexia C. Brasil, Claudia T. Marinho, Daniel R. Cardoso.
}

metodologia, ensino, projeto, criação

\begin{abstract}
A proposta deste artigo é apresentar os fundamentos de um projeto de pesquisa que esta sendo desenvolvido na UFC (Universidade Federal do Ceara), sobre os processos de criação que engendram o projeto de design. A partir de conceitos oferecidos por De Certeau - lógica das ações - e da metodologia de pesquisa oferecida pela Critica Genética - voltada para o estudo dos documento de processo da criação -, propomos uma abordagem processual do design. Buscamos, portanto, uma metodologia de projeto centrada na lógica das ações; como complemento daquelas metodologias de projeto, então centradas na lógica científica.
\end{abstract}

methodology, teaching, project, creation

The purpose of this paper is to present the notes of a research project that is being developed in the UFC (Federal University of Ceara), about the creative processes that engender the design project. From the concepts presented by De Certeau,-logic of actions - and the research methodology offered by the Critical Genetics - dedicated to the study of the document creation process - we propose a procedural approach to design. We seek, therefore, a design methodology centered on the logic of actions, in addition to those design methodologies, then focused on the scientific logic.

\section{Apresentação}

Sim. Há diversos métodos, combinamos de maneira diferente para cada projeto. Eles incluem: fazer uma lista; mudar de um projeto para o outro; ir sozinho para um café sem nada pra ler e ninguém pra encontrar e com vergonha de trabalhar (roubei essa técnica do diretor Steven Soderbergh); Stefan Sagmeinster, (MILLMAN, 2011)

A proposta desse artigo é apresentar os fundamentos de um projeto de pesquisa em desenvolvimento no Curso de Design da Universidade Federal do Ceará (UFC) sobre método, lógica de projeto, então relacionada às noções de criação e processo. As representações do projeto e as vivências cotidianas do designer constituem o corpus dessa pesquisa que tem como objetivo inicial apresentar fundamentos para uma metodologia de projeto centrada na lógica das ações.

O projeto proposto esta relacionado à sedimentação da pesquisa em design na Universidade Federal do Ceará (UFC) - Fortaleza - e tem como finalidade engendrar condições para criação de curso de pós graduação no Departamento de Arquitetura e Urbanismo na UFC, com foco nos processos de representação do projeto, a partir do reconhecimento e descrição do corpo de conhecimento gerado no curso de graduação de design, através da implementação de um Laboratório de Experimentação da Representação do Projeto ( LABRep).

Trata-se de um projeto de pesquisa que procura descrever uma metodologia de projeto que investe na exploração daqueles métodos de projeto não descritos - no entanto, previstos nas práticas cotidianas do designer - como fundamento para explorar as relações do designer com o seu cotidiano, considerando os mecanismos que ele emprega para dimensionar aspectos da pratica projetiva, que privilegia as minucias das ações-decisões do designer a partir de um olhar voltado para as novas formas de discurso que emergem da atividade de projeto. 
Esta pesquisa é financiada pelo CNPq, será desenvolvida ao longo de 36 meses e esta voltado para a criação e teorização de metodologias de projeto, a serem utilizados de forma auxiliar nas disciplinas Projeto Gráfico (PG) e Projeto de Produto (PP), que constituem o ciclo profissionalizante do curso de Design.

\subsection{Contexto gerador da pesquisa}

O curso de Design da Universidade Federal do Ceará, sediado em Fortaleza, foi criado em 2011 e teve a primeira turma ingressa no primeiro semestre de 2012. O seu projeto pedagógico, visando a adequação à demanda local, resultou na proposta de uma formação generalista abrangendo as áreas de projeto de produto e projeto gráfico.

As áreas de saber que compõem o curso, chamadas Unidades Curriculares, são: Projeto, Tecnologia e Humanística. Sendo que a unidade de Projeto abrange tanto as áreas de percepção e representação quanto à área de projeto gráfico e de produto. As disciplinas desta área têm por objetivo tanto estimular o aluno a desenvolver a percepção e a linguagem gráfica, assim como os meios de sua expressão criativa. Desta forma se propõe a congregar as atividades sintetizadoras de projeto em suas diferentes modalidades.

A não separação das disciplinas de representação e de projeto favorece a proposta de pensar o desenho no seu sentido mais amplo, como um dispositivo criativo, e ao mesmo tempo, pensar um contexto de aprendizado que investe no atelier de ensino - um ambiente distinto das salas de aula convencionais - como campo de reflexão na ação que promove uma postura ativa de estudo. Em termos concretos, isso significa dizer que embora no projeto pedagógico do curso haja uma maior concentração de disciplinas que tratam especificamente representação no primeiro ano do curso, entende-se que os problemas relativos ao domínio das ferramentas de representação não se encerram no ciclo de fundamentação. Ao contrário, o domínio representação acompanha as disciplinas de projeto que estão presentes em todo o curso.

Durante $o$ ano de fundamentação, com as disciplinas Projeto 1 e Projeto 2; nos quatro semestres de profissionalização com as sequências de Projeto Gráfico 1, 2, 3, 4 e Projeto de Produto 1, 2, 3, 4; e no último ano com a atividade Trabalho de Curso do ciclo de conclusão.

As problematizações que envolvem os estudos sobre metodologia de ensino e processo do design, associadas ao tema representação, demandam estratégias de pesquisas que possibilitem relacionar informações de diferentes campos de conhecimento, bem como a definição de um território de abordagem que procura pautar as áreas da educação, das artes, da sociologia, do design, da tecnologia.

A opção de implementar um laboratório voltado para a experimentação pedagógica, centrada no estudo da representação do projeto, justifica-se a partir da constatação da crescente interrelação entre as diferentes mídias e o projeto, o que incentiva uma revisão dos parâmetros de ensino do design, neste contexto.

Consideramos, portanto, para a elaboração e implantação deste laboratório de pesquisa, a importância de abordar:

- as potencialidades das ferramentas de representação digital e sua inegável repercussão no ato de projeto.

- a integração das ferramentas tradicionais-analógicos com as ferramentas digitais e os sistemas de informação e de comunicação, como estratégia para o designer desenvolver, expressar e partilhar suas ideias..

- a demanda de proposições de estratégias pedagógicas que estejam voltadas para a promoção do exercício da projetação em situações distintas, tendo em vista o uso diversificado de informações, métodos e tecnologias que auxiliem o aluno - em termos teóricos e práticos - nas tomadas de decisões e execução do projeto.

\subsection{LAbRep e a construção do perfil do profissional do design}

Não será somente no domínio da história que encontraremos os fundamentos para formar um profissional que esteja capacitado para identificar, descrever e resolver as múltiplas questões que 
Alexia C. Brasil, Claudia T. Marinho, Daniel R. Cardoso | Processo, representação e projeto: tópicos para uma metodologia de ensino de design fundamentada na ação e prática cotidianas

emergem hoje dos cenários contemporâneos de comunicação e produção de objetos, que envolvem as práticas do designer gráfico e de produto.

No curso no qual o projeto se insere, perseguimos, menos uma imagem do designer como profissional que tem por tarefa "resolver problemas", e mais a de um profissional, que comprometido com as dinâmicas do seu cotidiano, seja capaz de "problematizá-lo".

Formar um profissional da área do design hoje, para o nosso ponto de vista, comporta a elaboração de estratégias de ensino que possibilitem aos alunos do curso um conhecimento das práticas discursivas que estruturam a área - o que envolve as pesquisas e projeto de design bem como ser capaz de se apropriar delas, para a proposição de novos discursos - ou ainda, " novas formas de se comunicar" a partir do design.

Uma formação como esta investe na vinculação entre ação e comunicação, como parâmetro pra pensar o projeto. São estes os princípios que justificam a proposição do Laboratório de Experimentação da Representação do Projeto (LABRep), como primeiro passo para descrever uma metodologia de projeto centrada na lógica das ações.

As dinâmicas que envolvem as demandas cognitivas do designer e as formas de comunicação que ele elege para traduzir e comunicar uma idéia - sobretudo nas fases de concepção do projeto - aponta como tópico de reflexão as diferentes traduções que o designer faz do seu cotidiano, para formular ou resolver perguntas do projeto.

Os cadernos de notas de alguns designers deixam claro que o designer pensa o seu cotidiano a partir de estratégias distintas e que qualquer linguagem pode ser empregada ele, para tornar claras suas idéias. As notações iniciais de projeto, em particular, são discursos vinculados ao cotidiano que nos interessam, na medida que, vistos como código do projeto, são signos que revelam de que modo o designer opera a mediação entre os seus saberes e os textos sociais.

Se olhamos para esta notações e a relacionamos, podemos identificar, então, uma lógica que rege suas aquelas ações - implicadas nas atividades de leitura, seleção e articulação de informações, que engendram os processos do projeto, que, de algum modo revela que qualquer regra geral - como descritas pelos pressupostos do usuário ideal, do Estilo Internacional, e das regras a priori - para definir o processo do projeto, não contemplam os estudos sobre representação e comunicação, como um ideário básico que deve ser considerado para a formação do designer.

No entanto, para encaminhar as investigações vinculadas ao LABRep, não propomos um rompimento com a história do design, na medida em que a experiência de ensino do do grupo de professores proponente deste projeto, constata que os princípios propostos pelas metodologias clássicas de projeto sobrevivem ainda hoje - com força e pertinência na área do ensino. Sobretudo em situações na qual o professor tem que buscar fundamentos para pensar o ensino do projeto nos cursos que investe na formação de profissionais que irão atuar em áreas emergentes do design, como é o caso, do design de hipermídia, no final da década de 1990.

Como exemplo, temos o uso dos sistemas de grid - como amplamente divulgada pelos designers engajados com o Estilo Internacional na década de 1950-60 - e que foi retomado pelos designers envolvidos no desenvolvimento das interfaces gráficas, dos primeiros websites, estruturados pelo HTML, que "pensava" a estrutura das "paginas" em termos de tabela.

Relacionar, então, um corpo de conhecimento, descrito pela história do design, com aqueles gerados pelos profissionais formados pelas demandas do mercado, constitui o propósito principal do LABRep.

Como apreender, no campo do design gráfico, por exemplo, aquele conhecimento que foi gerado pelos designers gráficos ao aplicar seus saberes sobre projeto gráfico na criação de interfaces gráficas dos websites?

Ou seja, temos como desfio descrever um ideário de ações que constituem um corpo de conhecimento robusto, que foi banalizado, porque descrito como receituário de ações pelos profissionais que vivenciaram a tradução das metodologias "sabidas", para as novas situações de projeto. Desconsiderar este corpo de conhecimento significa assumir em termos teóricos, a prevalência do conhecimento teórico, sobre o conhecimento tácito, como fundamento para pensar estratégia de ensino do projeto. 
Alexia C. Brasil, Claudia T. Marinho, Daniel R. Cardoso | Processo, representação e projeto: tópicos para uma metodologia de ensino de design fundamentada na ação e prática cotidianas

Os estudos sobre representação e comunicação, que engendram as pesquisas vinculadas ao LABRep, propõem, portanto, uma vinculação entre diferentes áreas de estudo, para descrever um corpo de conhecimento sobre design, então fundamentado:

- pela dimensão interdisciplinar da prática do projeto.

- pelas implicações sociais do discurso do design.

- pelos valores intangíveis que constituem a prática projetiva.

\section{Estratégia teóricas para traçar um contexto de investigação sobre metodologia de projeto}

Com foco nos recurso que o designer emprega para traduzir e apresentar suas idéias, discorremos sobre as relações entre comunicação, ação e cotidiano, para refletir sobre os processos do designer.

Em termos históricos identificamos que, se em primeiro momento - no período pós guerra - o designer foi convocado para rever e prever dinâmicas de produção-comunicação em massa, mas hoje ele é convocado para pensar novas soluções sobre as relações do sujeito com o seu contexto.Se alinhamos ás atuações do designer, como descrito no pos Guerra - ao cenário no qual o designer atua hoje, vemos que que as teorias sobre projeto que investiram na incorporação da lógica da ciência para legitimar a prática do designer, demandam novos modelos, que, não se associam propriamente ás metodologias oferecidas pelas ciências sociais, mas, antes disso, conta com os seus resultados para traçar uma metodologia própria, que esteja fundamentada sobretudo, pelo pressuposto de que pelo viés das práticas cotidianas o designer revê, atualiza e define novos métodos de projeto.

Ao descrever o processo de colonização da América Latina pelos espanhóis, DeCerteau aponta caminhos, identificando de que modos os nativos burlavam as regras impostas pelos colonizadores, incorporando as regras impostas aos seu rituais cotidianos. As argumentações de De Certeau ainda que endereçadas para descrever um contexto específico - para pensar a colonização pelas mídias - são decisivos para a nossa pesquisa, na medida em que aponta caminhos para pensar estratégias para pensar as dinâmicas que envolvem a construção de uma identidade do designer hoje.

A idéia de apropriação - como estratégia de construção de identidade - faz parte também do ideário da antropofagia - como definida por Oswald de Andrade. Uma estratégia poética que também levamos em conta no desenvolvimento desta pesquisa, para identificar os dispositivos de fuga que o designer inventa para burlar as regras de projeto, sem, no entanto, por em risco sua integridade profissional e ao mesmo tempo investir na definição as sua identidade - por revelar os contextos nos quais os projeto foram desenvolvidos.

Este pensamento, vinculado aos estudos e estratégias oferecida pela Crítica de Processo, como proposto por Cecília Salles (1994), mostra-se como uma ferramenta "poderosa" para pensar estratégias de ensino que invista em um pensamento compromissado em associar prática e teoria, conhecimento técnico e tácito, poética e técnica.

\section{Estratégias para pensar uma metodologia de projeto centrada na lógica das ações.}

A partir das contribuições trazidas pela Critica Genética - vinculadas às teorias sobre o cotidiano buscamos como resultado do conjunto das investigações a serem realizadas no LABRep, nos próximos três anos, reunir fundamentos para propor uma metodologia de projeto centrada na lógica das ações.

Em termos conceituais, apresentamos como temas motivadores da pesquisa:

- Deslocar as discussões sobre metodologia de projeto do eixo do pensamento científico para um eixo que privilegie uma ética e uma lógica do cotidiano;

- Possibilitar o reconhecimento das representações do projeto, as notações iniciais ou croquis como formas visíveis de um pensamento em construção, dotado de uma lógica própria; 
Alexia C. Brasil, Claudia T. Marinho, Daniel R. Cardoso | Processo, representação e projeto: tópicos para uma metodologia de ensino de design fundamentada na ação e prática cotidianas

- Tornar visível um corpo de conhecimento, muitas vezes não descrito e organizado, produzido ao longo do desenvolvimento do projeto.

Temos como objetivo principal reunir argumentos para uma aproximação entre os processos do artista e do designer, de modo a oferecer para este, para professores de projeto e pesquisadores, caminhos para identificar nos processos da arte e nas dinâmicas do cotidiano de trabalho de profissionais envolvidos com a criação, referências para elaborar uma metodologia de projeto que esteja alinhada às complexidades dos contextos de produção contemporânea. Buscase, portanto, uma compreensão do design como modo de organizar e partilhar informação, a partir de uma abordagem que amplia as fronteiras do design, como prática e disciplina.

\subsection{Contribuições da Critica Genética}

As metodologias clássicas de projeto de design, em um primeiro momento parecem ser eficientes para abordar as dinâmicas produtivas e as demandas comunicativas na década de 1960. Mas nas situações de projeto,prescritas como possibilidade de comunicação para o designer, a partir da década de 1990, privilegia-se a decantação do problema de projeto.

Incorporar as variações, erros e os acasos, já não se traduzem mais como falha do projeto nem falta de uma estratégia adequada para formatar o artefato - mas, ante disso, potencias de ações, que implicadas no projeto, traduzem as atividade, empregadas pelo designer, para acolher, identificar e descrever, repertórios e informações que irão sustentar e constituir a suas práticas.

A Crítica Genética é uma área de estudo que surgiu na França em 1968, a partir das investigações de manuscritos literários de escritores como Flaubert. Nas duas últimas décadas, por iniciativa do CECG - PUC ISP - começaram a surgir pesquisadores interessados em estudar os documentos de processos de outras áreas; como as artes, a fotografia, a publicidade, etc. bem como para aplicar os conhecimentos reunidos a partir destas pesquisas em investigações sobre a educação e a curadoria de arte.

O objetivo da Crítica Genética é oferecer uma nova possibilidade de abordagem das "produções" que tem a criação como mote, como é o caso do design, em busca de um fundamento lógico para descrever as diferentes logicas de processo - na arte, na fotografia no cinema, na arquitetura, no design.

Como estratégia de investigação, a Critica Genética possibilita um tratamento metodológico das informações do projeto e oferece caminhos para abordar as notações de projeto em busca de fundamentos para refletir sobre as práticas do designer.

A metodologia oferecida pela Crítica Genética, com fundamentos na semiótica peirceana, como proposto por Salles, ao investir em uma noção ampliada de comunicação, para abordar os processos criativos em diferentes áreas, mostra-se como uma ferramenta poderosa para abordar o projeto, como proposto neste projeto de pesquisa. Na medida em que possibilita compreender, a partir do estudos sobre representação, os sistemas de informação e as dinâmicas comunicativas que estruturam "os discursos" do projeto, bem como identificar as estratégias que s]ao empregadas pelo designer para se apropriar dos discursos de outras áreas.

\subsection{Contribuições dos estudos sobre o cotidiano}

Podemos afirmar que o tempo todo métodos são criados a partir dos significados que o designer vai atribuindo - seja pelos hábitos ou rituais de trabalho - ás ações mais corriqueiras que compõem os acontecimentos diários da sua vida profissional. No entanto, diluídos no cotidiano, estes métodos não são inteligíveis fora de uma metodologia que tenha os pressupostos do processo, e das construções que o engendram, como parâmetro.

Sendo assim buscamos fundamentos teóricos para tomar como foco as construções cotidianas do designer para, a partir delas, descrever a lógica que define o modo como o designer se apropria das regras e princípios do projeto, que são passados a ele em seu período de formação, para construir um modo próprio de projetar.

Em a Invenção do Cotidiano (1994), Michel De Certeau descreve uma "teoria das práticas" cotidianas, das quais empregamos alguns termos e conceitos para refletir sobre a prática do designer. Neste trabalho, De Certeau aborda as "maneiras de fazer" do homem comum, como forma de "resistências" em relação ao desenvolvimento sócio cultural. Segundo ele, haveria em contraposição a uma produção racionalizada, uma outra, que qualificada pela dinâmica do 
Alexia C. Brasil, Claudia T. Marinho, Daniel R. Cardoso | Processo, representação e projeto: tópicos para uma metodologia de ensino de design fundamentada na ação e prática cotidianas

consumo, provocaria fissuras e desvios não previstos pelo conjunto de ordens e ações definidos pelos sistemas de regras sociais.

As investigações de De Certeau estão inseridas em uma área de pesquisa definida com "estudo do cotidiano". Seu objetivo é propor um debate que entrelace o cotidiano enquanto categoria de análise, com o cotidiano enquanto categoria de vida, para trazer visibilidade para a complexa trama urdida nos processos de reprodução social, de acomodação ou de tomada de consciência.(Levigard, 2011)

Dentre os diversos conceitos oferecidos por De Certeau para descrever de que modo se operam as relações entre produção e consumo, pelo substrato da resistência, buscamos a noção de bricolagem - empregada por ele para descrever as micro-negociações nas quais o sujeito investe para relacionar e se apropriar dos diferentes regimes de regras do sistema -, para relacionar as regras de ofício e as práticas cotidianas no design, para o reconhecimento de uma produção secundária de princípios que resulta dos processos de utilização e de apropriação das regras do projeto - como definidos pela história, por teóricos ou mesmo pelo mercado.

Nas palavras de De Certeau, estas construções secundárias devem ser vistas com a " construção de frases próprias com um vocabulário e uma sintaxe recebidos”.(De Certeau, 1996, p. 93).

Supondo que, pelas maneiras de usar os princípios dados pelas invenções cotidianas, pelas maneiras de fazer, ocorreria com o designer uma "bricolagem"dos discursos dominantes sobre design. Pela possibilidade de descobrir inúmeras metamorfoses dos princípios sedimentados, segundo seus interesses próprios e suas próprias regras.

O conceito de bricolagem é então oferecido por De Certeau para definir, repectivamente "as modalidades da ação" e as "formalidades das práticas", pelos termos tática e estratégia; as táticas desviacionistas, então relativas ás possibilidades oferecidas pelas circunstâncias, não obedecem a lei do lugar, sendo que as estratégias tecnocráticas, visam criar lugares segundo modelos abstratos. (De Certeau, 1994)

Segundo De Certeau, o que distinguiria uma da outra são os tipos de operação nestes espaços que as estratégias são capazes de produzir, mapear e impor, ao passo que as táticas só podem utilizá-las, manipular e alterar. (De Certeau,1994, p. 92)

A idéia de lugar no entanto, não esta necessariamente ligada a uma noção topológica, mais que isso, define contextos de construções mentais e discursivas.

Uma compreensão do como se operam estas construções de segunda ordem que resultam das articulações entre táticas e estratégias, demandaria, segundo o autor, identificar as diferentes maneiras de fazer, que como estilos de ações, "intervêm em num campo que os regula num primeiro nível, mas introduzem ai uma maneira de tirar partido dele, que obedece a outras regras e constitui como que um segundo nível imbricado no primeiro" (De Certeau,1994, p. 92)

Assim, podemos pensar as maneiras de projetar (uma cadeira ou um livro) a partir de diferentes modelos - Circular ( Bob Borzak), Feed Back (Bernhard E. Bürdek), linear ( Bruce Archer) (Vasconcelos, 2009) - mas sem perder de vista as ações particulares dos designers que se impõem, de modo que a partir desta combinação, acabe criando para si uma situação para as maneiras de utilizar uma ordem "imposta", no entanto sem abrir mão dos princípios definidos para instaurar pluralidade e criatividade no seu processo.

\section{Possibilidades teóricas para acolher nos estudos sobre projeto as ações e a representação como parâmetro para pensar o projeto}

A lógica das ações, empregada para fundamentar uma metodologia de projeto, tem como pressuposto a existência de uma cultura do projeto, então centrada no discurso (Krippendorf, 2001); a possibilidade de pensar o cotidiano como espaço de criação (De Certeau, 1994) e o reconhecimento das representações do projeto como registro de um pensamento em construção (Salles, 1992).

Os discursos do design e sobre design, que são formulados no calor das ações do cotidiano de trabalho - seja pelo designer e por aqueles que de algum modo estão vinculados ao desenvolvimento de um artefato - descrevem, quando relacionados, um processo coletivo de 
Alexia C. Brasil, Claudia T. Marinho, Daniel R. Cardoso | Processo, representação e projeto: tópicos para uma metodologia de ensino de design fundamentada na ação e prática cotidianas

construção de conhecimento - guiado por uma disposição para a comunicação igualmente coletiva - muitas vezes voltadas para a criação de novos modos de projetação.

Neste sentido, pensar uma metodologia do projeto fundamentada pela lógica das ações, implica em pensar a prática de projeto como atividade comunicativa - como já foi dito - mas também reconhecer que os métodos de projeto, descritos e sistematizados, perdem a asua pertinência se não forem validados avaliação critica das ações que são endereçadas para o desenvolvimento de projetos específicos.

Fica evidente que devemos considerar como corpo de conhecimento os quais devemos tomar como fundamento para elaborar estratégias de ensino de projeto, um conjunto de práticas - plurais e heterogêneas - que emergem do cotidiano, estas, que nem sempre se mostram visíveis nas formas finais do artefato ou nas fases finais do projeto, mas que no entanto estão corporificadas nas notações iniciais do projeto e pelas ações realizadas pelos designers. Sendo assim, recorremos ás concepções de projeto, como propostos pelos autores, Vera Nojima, Lawson, Dijon de Moraes (2010), Maria Ledesma (2005), Klauss Krippendorf (2001) e Benhard Burdek(2006) e Buchanan (2001). Para realizar as aproximações conceituais que nossa investigação demanda, no que se refere ás relações entre projeto, criação e comunicação.

Começamos pelo conceito de "gestão da complexidade", como apresentado por Moraes (2010), empregado para caracterizar a atuação do designer nos cenários de produção atuais.

Essa noção é empregada como referência para descrever o contexto no qual se desenvolvem nossas investigações. Na medida em que torna evidente que as ações criativas do designer hoje estariam muito mais voltadas para invenção de novas maneiras de fazer projetos - gerenciar informações - do que para novas formas de artefatos - gerenciar processos de produção.

Para Moraes, os cenários de produção do designer hoje - múltiplos, fluidos e dinâmicos teriam levado o designer a aprender a lidar com o excesso de informações, o que significa "valerse de novas ferramentas, instrumentos e metodologias para a compreensão e a gestão de complexidades" (Moraes, 2010:13) - que caracterizam os contextos culturais contemporâneos as quais ele descreve a partir do conceito de metadesign (projeto voltado para a elaboração de estratégias de projeto).

Diante da constatação da necessidade de elaboração de novas ferramentas criativas para o processo atual de design - considerando os modelos até então praticados para a concepção dos artefatos - busca-se, através desta pesquisa, ampliar o campo de reflexão sobre o tema, no sentido de reunir conceitos e metodologias para inserir os estudos sobre o processo e sobre o cotidiano no contexto de discussão sobre metodologia de projeto.

Sendo assim, buscamos no conceito de prática cotidiana como apresentado por De Certeau (1994) e a estratégia de pesquisa oferecida pela crítica genética, como descrito por Salles (1992) como referências para descrever uma metodologia de projeto fundamentada por uma lógica das ações, para então apresentar os mecanismos empregados pelo designer para tornar como produto de suas práticas projetivas "novas formas de projetar".

Em termos de estratégia de pesquisa, propomos relacionar as representações do projeto, definidos como documentos de processo (Salles,1992) e as ações profissionais do designer definidas pela noção de "prática cotidiana" (Certeau, 1994) para descrever as estratégias que são inventadas pelo designer ao ter que articular diferentes linguagens, meios e recursos que constituem territórios de conhecimentos que extrapolam o campo do design.

Podemos inferir que o desenvolvimento do projeto hoje esteja ancorado também em informações as quais o designer deve aprender e articular para resolução de um problema particular. Nesse sentido, parece aproximar-se da prática do artista. No que se refere à invenção de processos.

A invenção de processos foi uma tônica da arte moderna sistematizada pelas vanguardas pelo viés dos manifestos. Foi sintetizada nos anos 60 pelos artistas minimalistas, na busca de um discurso essencial da arte. Como uma vertente da arte conceitual, iniciada por Duchamp, essa forma de arte realiza iniciativas que buscam identificar a forma material, os sentidos e a realidade do projeto a partir de um programa muitas vezes centrado em um plano de ações que se mostrava como caminho de uma vivência estética. Assim como evidencia o próprio fazer como construção artística. (Archer, 2001) 
Para o nosso ponto de vista, esta face da arte que se tornou visível a partir da primeira metade do século XX mostra-se como emblemática para a identificação dos processos da arte como corpo de conhecimento passível de descrição e de apropriação por outras formas de produção que tem a criação como parâmetro, como é o caso do design. Desta forma, a prática artística aqui chamada, é também ela contemporânea e se traduz na prática cotidiana. Já descartando as correlações de aura e valor atribuídos ao objeto de arte, e focando, sobretudo, nos modos de fazer. O que irá interessar como paralelo com a arte é a potência criativa do seu fazer, como método de recriar métodos.

Nojima (2006), em defesa dos estudos das linguagens como apoio aos processos metodológicos do design, traça um cenário no qual relaciona os métodos de pesquisa das ciências sociais e do projeto, como fundamento para afirmar que não haveria um consenso para a adoção dos métodos em cada um destes campos. Citando Santaella argumenta que esta falta de consenso faz supor que, em ambos os casos, devemos pensar que as metodologias são específicas, na medida em que variam de acordo com momento histórico no qual são desenvolvidas, bem como na passagem de uma ciência - ou projeto - para outra.

Argumenta então que o designer pode se valer da aplicação de metodologia da investigação e da análise das linguagens, na medida em as várias modalidades produtivas do design, vistas então como fenômeno de linguagem, mostram-se como pressupostos para definir de que modo, "são construídos os significados que modelam e reorientam os mais diversos discursos resultantes dos processos do Design" (Nojima,2006:124)

A partir desta afirmação, Identificar as formas de representação que são empregadas pelo designer em relação às dinâmicas que definem as suas práticas cotidianas,levariam a uma abordagem processual do projeto. Trata-se, portanto, de um recurso de investigação que pode ser empregado para descrever as estratégias que são inventadas e inventariadas pelo designer, ao ter que articular, durante o desenvolvimento do projeto, diferentes linguagens, meios e recursos, para resolver os problemas que a ele se apresentam.

Como afirma, Nojima (2006), para realizar pesquisa ou projeto em design, É necessário conhecer as teorias que o embasam, os métodos de projetação que emprega e familiarizar-se com as diferentes situações de contextualização em que é ou pode ser utilizado. (ibdem : 123)

As situações de contextualização, a qual a autora se refere, é um fator que nos faz pensar sobre as distintas situações que se apresentam quando abordamos o tema projeto, no contexto de ensino. Esse cenário é descrito, por exemplo, por Lawson, quando aponta que o ateliê (físico e conceitual), tem sido empregado, como principal estratégia de ensino de projeto nas escolas, hoje.

No entanto, estes ateliês, segundo ele, então fundamentados no principio do "aprender fazendo" - no qual os alunos recebem uma série de problema $s$ de projeto para resolver privilegiam a noção de projetar como prática, em detrimento aquela centrada em estudos e análises. Para ele, o método do ateliê, tende a privilegiar o foco no produto final do trabalho, não estendendo, de forma suficiente, uma reflexão sobre o processo.

Concordamos parcialmente, com o pensamento de Lawson, em um sentido, descordamos dele porque acreditamos que os ateliês podem ser pensados como um recurso pedagógico que promova reflexões criticas sobre o processo do projeto. Um recurso que contribui para a preparação dos nossos alunos para atuar nos contextos futuros que os esperam, como profissionais.

Em outro sentido, concordamos com Lawson quando afirma que "os projetistas de hoje não podem ser treinados para seguir um conjunto de procedimentos, já que os ritmos das mudanças do mundo no qual tem que trabalhar logo os deixaria para trás" ( Lawson, 2011: 18)

Para a formação do profissional que trabalha com projeto hoje (como o arquiteto e odesigner), o ideal é, ao invés de buscar uma formação fundamentada na tradição do ofício, criar estratégias de ensino que possibilitem ao aluno aprender a avaliar e aproveitar as possibilidades oferecidas, pelas novas tecnologias, bem como, os conhecimento locais e cotidianos, definidos pelas dinâmicas do cotidiano.

Ledesma (2005), em um estudo no qual relaciona os estudos do design aos da comunicação, afirma que o design seria muito mais do que uma atividade voltada para maquiar o produto ou a imagem, "trata-se de uma atividade que dá categoria de existência ao mundo dos objetos tal como o conhecemos; é a atividade fundante da ordem atual das coisas". (Ledesma, 2005:32). Seria ele 
Alexia C. Brasil, Claudia T. Marinho, Daniel R. Cardoso | Processo, representação e projeto: tópicos para uma metodologia de ensino de design fundamentada na ação e prática cotidianas

responsável por construir a visibilidade contemporânea, pela definição dos modos de leitura e de apreensão dos códigos culturais, sendo portanto elemento chave para a construção das relações sociais:

O design é uma atividade de projeto em duplo sentido: se projeta internamente sobre a obra a partir de sistemas semióticos que Ihes são próprios e, a partir desta projeção, projeta formas de relações sociais (Ledesma, 2005, p. 32).

Haveria, segundo ela, uma carência de estudos voltados para a identificação dos efeitos do discurso do design nas construções do cotidiano - como por exemplo, de que modo ele se traduz como fator decisivo na determinação dos modos de habitar - e elenca três fatores como causas das fronteiras limítrofes dos estudos sobre design hoje: uma união mecânica entre designtecnologia-produção e mercado; o fato de que as reflexões sobre a produção do design (objeto, a imagem e o visual), em geral, evitam considerações sobre o processo do projeto.

Tomamos como foco este último fator para definir o escopo teórico de nossa pesquisa. Tendo em vista os estudos sociais e genéticos, para dar visibilidade aos processos do projeto de design, acolhemos as dinâmicas do cotidiano, como recurso para relativizar algumas contraposições conceituais que são ainda empregada nas discussões sobre projeto, hoje. Como afirma Ledesma:

A sobrevivência da antiga divisão entre teoria e prática, entre intelligenstsia e realização, o pensamento sociológico, filosófico ou semiótico em geral tomou em consideração os produtos do design - imagens, objetos em geral, filmes - algumas de suas disciplinas - arquitetura, publicidade gráfica - ou seus efeitos, sem considerar o conjunto da atividade projetual. (Ledesma, 2005: 32).

O conjunto da atividade projetual compreende um percurso produtivo que engloba a concepção, descrição e construção do artefato, bem como o seu uso. Mas acontece que, no contexto contemporâneo, estas etapas se misturam; sobretudo se consideramos, por exemplo, a produção de softwares e as suas versões demo, cujo desenvolvimento estaria condicionado ás ações - uso - do usuário.

Se, por um lado, podemos considerar uma metodologia de projeto que acolhe as lógicas do cotidiano pelas dimensões do produto - como proto-projeto que é definido pela ação do usuário. Por outro, seguindo um caminho em direção ao processo, identificamos as ações do designer como seu principio norteador (Moraes, 2010).

Para entender melhor o contexto da pesquisa convém considerar que a lógica cientifica clássica - baseada no método indutivo - foi o parâmetro empregado pelos primeiros estudos sobre metodologia de projeto, nos anos de 1960. Vinculados à HFG Ulm. Desde então, como demonstra Krippendorf (2001) e Burdek (2006), novos modelos foram empregados por conta dos novos contextos de produção e de comunicação, gerados pelo cultura de consumo, pelo pressuposto da identidade, pela linguagem digital, pela retórica. Novos modelos surgiram a partir do reconhecimento de que uma metodologia de projeto, descrita como etapas lógicas - então voltadas para a produção do produto - já não pareciam mais suficientes para cobrir as demandas tecnológicas e culturais que apareceram nos períodos subsequentes à década de 1960.

Para Krippendorf, as mudanças dos paradigmas de projeto ao longo do século XX ocorreram após um século de disputas concorrentes entre arte e design, quando o design, então, "enveredou por uma trajetória irreversível própria do design, devido a supressão dos modelos ou exemplares modelos" (Krippendorf, 2001, p.88). O que teria resultado, segundo ele, no deslocamento do eixo de abordagem do design da cultura científica para a cultura do projeto. $\mathrm{O}$ autor, então, apresenta os termos, objeto, identidade, interface e discurso, para identificar os novos modelos conceituais do paradigma do projeto de design; os quais teríamos vividos e estaríamos prestes a viver. (Krippendorff, 2001)

Para Burdek (2006), as mudanças dos paradigmas de concepção do projeto estariam vinculadas ao aparecimento de novos modelos do pensamento científico - promovidas, sobretudo, pelos estudos realizados por Feyrabendt e Kuhn - definindo assim, um deslocamento da noção de projeto centrada nas ciências naturais, para as ciências sociais.

Ambos os autores - Krippendorf e Burdek - parecem concordar que as formas de abordagem do projeto do design, desde o inicio de sua teorização, seguiram uma tendência que esteve centrada na concepção do produto, para seguir um caminho em direção ao social e ao ser 
humano. Essa mudança significou novas formas de pensar o projeto, definindo parâmetros que não são necessariamente excludentes, na medida em que vemos que ambas formas de conceber o projeto são aplicadas hoje.

No caso de nossa pesquisa, o parâmetro do discurso, como apresentado por Krippendorf (2001), é tomado como medida para pensar as relações entre os novos paradigmas de projeto e as estratégias de ensino de design tendo as ações do cotidiano como parâmetro do projeto. $O$ discurso, associado á pratica projetiva, parece ser uma radicalização da concepção de projeto voltado para o ser humano, na qual as práticas do designer e seus discursos passam a ser incluídos como fatores determinantes para definir o projeto.

Nesse sentido, podemos afirmar que a inserção do discurso do design no contexto da cultura contemporânea levou o designer dimensionar as suas práticas como recurso voltado para a proposição de novas ferramentas criativas, para poder então lidar com a quantidade e variedade de informações - topográficas, subjetivas, contextuais. Constatação que nos faz identificar, como afirma Moraes (2010), a prática do designer como gestão de complexidades. Ou seja, a capacidade de reconhecer e de articular discursos de naturezas distintas, para a proposição de novos discursos, define uma situação de projeto, no qual o designer passa a vincular as suas ações á invenção de mecanismos para poder lidar com as informações que emergem dos contextos de produção e de comunicação, que definem novos contornos para o seu cotidiano profissional.

Voltado então para a construção de artefatos e de processos, o projeto de design hoje, potencializaria o dado da criação como formas de "narrar modos de vida imagináveis" (Krippendorf, 2001). Fato este que, segundo, aproximaria a prática do designer a do poeta, dos escritores de ficção científica e sonhadores ou poderiam ainda estar inspirado neles; mas com a diferença que as ficções do designers devem ser realizáveis, devem introduzir mudanças no mundo (Krippendorf, 2001:94)

Pensar, portanto, sobre a formação do designer em um cenário no qual o design é abordado como prática discursiva, faculta em uma cultura de projeto que acolha o conhecimento dos outros, não como descrito nas pesquisas de mercado que busca definir um perfil de usuário-consumidor, mas a partir de um foco que aceite múltiplas perspectivas de conhecimento descritos pelas ações cotidianas de grupos, sujeitos e profissionais e suas vinculados com o discurso do design.

\section{Considerações finais}

A tarefa de estruturar um curso de graduação não é simples e a situação fica um pouco mais complexa quando a área contemplada é relativamente nova e carece de teorias próprias, como é o caso do design.

No processo de estruturação do curso de Design na UFC, ficou evidente para nós professores que para a formação de profissionais engajados e compromissados com as demandas do contexto contemporâneo, o mais apropriado seria definir estratégias pedagógicas que possibilitassem o exercício da projetação em situações distintas e o conhecimento da diversidade de informações, métodos e tecnologias que são oferecidas hoje, para o desenvolvimento o projeto. No entanto, não encontramos um corpo de conhecimento devidamente organizado para cumprir nossas expectativas sobre o curso, no que se refere a uma metodologia de projeto que privilegiasse as dinâmicas locais e as ações identitárias do designer.

A proposta de criar um Laboratório de Experimentação da Representação do Projeto (LABRep), voltado para a prática do ensino, vem na direção de reunir um corpo de conhecimento que nos auxiliem a construir a construir uma identidade do curso, tendo como foco os processos.

Dai então a importância de pensar um espaço de práticas que promovesse a atualização dos discursos sobre os meios de representação aplicados ao projeto, considerando as conexões possíveis entre as ferramentas analógicas, as ferramentas digitais, os sistemas de informação e de comunicação, para cotejar os conhecimentos sobre método e criação, para formar profissionais capazes de desenvolver, expressar e partilhar suas ideias, a partir de qualquer meio disponível.

As problematizações que envolvem, os estudos sobre metodologia de projeto estão vinculados àquelas voltadas para o ensino, a partir das rubricas da cognição, imagem e tecnologia. Neste sentido, identificamos que ao empregar as estratégias de pesquisa oferecidas pela Crítica 
Genética - ao tomar como foco de investigação os documentos de processo - trazemos como contribuição para os estudos sobre projeto - desenvolvimento e ensino - os estudos sobre criação, com foco nas soluções que o designer inventa e emprega para construir o seu cotidiano de trabalho.

Abordamos, portanto os registros de projeto como modos de troca de informações que são empregados pelo designer, ao se relacionar com o seu contexto. Mas que no entanto, não podem ser previstos ou definidos a priori. Assim como há estilos de escrever, há também estilos|maneiras de se fazer um projeto. Estes estilos|maneiras nem sempre se mostram visíveis nas formas finais do artefato projetado, no entanto, podem ser descritos a partir de uma leitura do conjunto de informações que são geradas ao longo do desenvolvimento do projeto.

Reconhecer o corpo de conhecimento então corporificado pelas notações de projeto, pode ser um caminho para o professor -pesquisador - preocupado em elaborar estratégias de ensino sobre projeto no campo do design - para relacionar os métodos oferecidos ás dinâmicas locais de ensino, relacionando os diferentes e diversificados métodos que emergem das construções cotidianas do designer.

Ainda que sejam eles, muitas vezes de caráter temporário e marcado pela imprevisibilidade, são conhecimentos importantes que devem estar previstos em nossas práticas de ensino. As imagens e relatos que emergem da prática do projeto revelam também os imaginários cotidiano e produtivo sobre design.

Então, como propor uma metodologia de projeto que procura abarcar um conjunto de métodos que se recusa a ser descrito a partir de um conjunto de regras ?

Como descrever um conjunto de princípios temporários que "regram" de, alguma forma, as relações do designer com o seu contexto, mas que se apagam quando o projeto é concluído?

São estas as perguntas norteadoras para propor uma metodologia de projeto centrada na lógica das ações. Na medida em que um conhecimento projetivo, em estado latente, como inscrito nos contextos cotidianos, é para o educador matéria valiosa para elaborar, pensar e partilhar o design como atividade comunicativa. Mas trata-se de um conhecimento que se mostra como matéria bruta para o educador, ele se esconde nos lugares, nos objetos, nas formas, nas ações e nas relações entre eles, para definir um discurso.

Se a educação do design é o lugar em que estudantes de design aprendem um modo de falar e de pensar próprios do designer, como afirma Krippendorf (2001), considerar uma metodologia de projeto que encontra nas lógicas das praticas cotidianas seus fundamentos, parece ser um caminho necessário para identificar os discursos a serem apreendidos pelos nossos alunos.

\section{Referência Bibliográfica}

BURDEK, Bernhard. 2006. Design: História, Teoria e Prática do Design de Produtos. São Paulo: Edit. Blucher.

CARDOSO, Rafael. (Org.) 2005. O design brasileiro antes do design: aspectos da história gráfica, 1870-1960. São Paulo: Cosac Naif.

ARCHER, Michael. 2001. Arte Contemporânea, uma história concisa. São Paulo: Martins Fontes.

De CERTEAU, Michel. 1994. A Invenção do cotidiano. Artes de fazer. Petrópolis: Vozes,

KRIPPENDORFF, Klaus. 2001. Design centrado no ser humano: uma necessidade

cultural. In: Estudos em Design. v.8, n.3 (maio). Rio de Janeiro: Associação de Ensino de Design do Brasil. p. 87-98.

LAWSON, Bryan. 2011. Como Arquitetos e Designers Pensam. São Paulo: Editora: Oficina de Textos.

LEDESMA, Maria. 2005.Diseño y comunicacion. Buenos Aires: Paidos.

LEVIGARD, Yvonne Elsa; Ruth Machado Barbosa. 2011. Incertezas e cotidiano: uma breve reflexão. Arquivos Brasileiros de Psicologia, v. 63, n. 3.

MEGGS, Phillipe.2011. História do design gráfico. São Paulo: CaossacNaify. 
Alexia C. Brasil, Claudia T. Marinho, Daniel R. Cardoso | Processo, representação e projeto: tópicos para uma metodologia de ensino de design fundamentada na ação e prática cotidianas

MILLMAN, Debbie. 2011. Grandes designers \& suas mentes criativas. São Paulo: Rosari.

MORAES, Dijon de. 2010. Metaprojeto: o design do design. São Paulo: Blucher.

NOJIMA, Vera Lucia . 2006. Os estudos das linguagens como apoio aos processos metodológicos do design. In: Luiz Abtônio Luzio Coelho. (Org.). Design: Método. Rio de Janeiro: Novas Idéias. PUC-Rio, p. 18-46.

SALLES, C.. 1992. Almeida. Crítica Genética. São Paulo: Educ.

VASCONCELOS, Luis. 2010. Um Modelo de Classificação para Metodologias de Design. ANAIS do $9^{\circ}$ Congresso Brasileiro de Pesquisa e Desenvolvimento em Design, 2010.

\section{Sobre os autores}

Aléxia Brasil, Universidade Federal do Ceará, Doutora em Comunicação e Semiótica, pela PUC$\mathrm{SP}$, desenvolve pesquisa sobre representação e ensino de projeto, no design e na arquitetura, atua nas áreas do design gráfico e das artes visuais, com publicações em anais de importantes congressos sobre arte e design (ANPAP e P\&D) e participação de desenvolvimento de projetos editoriais relacionados a arte e cultura visual.

Claudia Teixeira Marinho, Universidade Federal do Ceará. Doutora em Comunicação e Semiótica, pela PUC-SP, desenvolve pesquisa sobre os processos de criação na arte e no design, desenvolve pesquisa os processos de criação na arte e no design, com publicações em importantes periódicos da área do design (Revista Estudos em Design, Revista Triades), em capítulos de livros e anais de congresso, sobre temas relacionados a arte e design.

Daniel Ribeiro Cardoso, Universidade Federal do Ceará.Doutor em Comunicação e Semiótica, pela PUC-SP, arquiteto, desenvolve pesquisa em novas tecnologias e processos contemporâneos de projeto, na linha de percepção e representação., com publicações em periódicos e anais, relacionados ás áreas da representação e arquitetura.

[Artigo recebido em dezembro de 2012, aprovado em dezembro de 2012] 